\title{
Oiled Brain and Status Epilepticus: Intraventricular and Subarachnoid Rupture of a Temporal Dermoid Cyst
}

\author{
Moncef Berhouma
}

\begin{abstract}
Intracranial dermoids are rare slow-growing tumors. Generally, they are revealed after they reach a considerable volume, leading to the compression of neural structures. Exceptionally, these inclusion tumors can rupture spontaneously within the subarachnoid, intraventricular or subdural spaces. We present the case of a ruptured temporal dermoid cyst with intraventricular, subarachnoid and subdural spread, revealed by status epilepticus in a 25 -year-old woman. The treatment of such tumors should be surgical, with the aim of a total removal when feasible. Recurrence of subtotally removed dermoids remains exceptional. The chemical irritation of the cortex but also the vasospasm induced by the fat droplets spread might induce seizures.
\end{abstract}

Keywords: Intracranial dermoid cyst; Magnetic resonance imaging; Rupture; Status epilepticus

\section{Introduction}

Intra-cranial dermoids are rare benign congenital neoplasms. They result from the incorporation of ectopic cell rests into the closing neural tube, essentially near the midline, involving usually the parasellar region or the posterior fossa. Their slow growth and good prognosis even after subtotal removal are characteristic. Exceptionally, dermoids can express acutely after they rupture spontaneously within the subarachnoid or intraventricular spaces. This complication was classically considered as fatal, but the development of imaging diagnosis tools led to the multiplication of such cases [1].

Manuscript accepted for publication October 29, 2010

Department of Neurosurgery B, Pierre Wertheimer Neurological and Neurosurgical Hospital, 59 Boulevard Pinel 69677 Bron Cedex, Lyon, France. Email: berhouma.moncef@yahoo.fr

doi:10.4021/jmc72w
We describe the case of a dermoid cyst rupture within the ventricles, the subarachnoid spaces and even subdurally, in a young woman presenting with status epilepticus.

\section{Case Report}

A 25-year-old woman, without any previous medical history, presented with prolonged status epilepticus. She was admitted to our emergency room after 2 hours of uninterrupted seizures and she was still unresponsive and having right hemiconvulsions resistant to intravenous Diazepam and Phenytoin. She was given thiopenthal and intubated, which

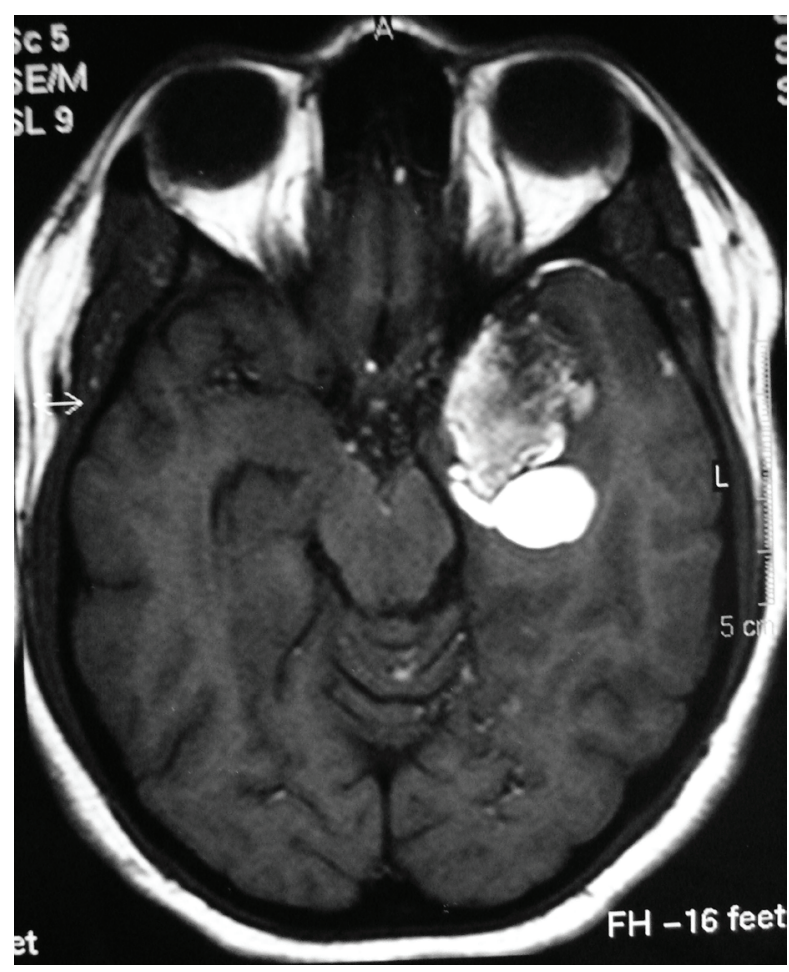

Figure 1. Axial T1-weighted sequence without gadolinium showing a left temporal heterogeneous mass with hyperintense droplets in the basal cisterns and in the left temporal tip subdural space. 


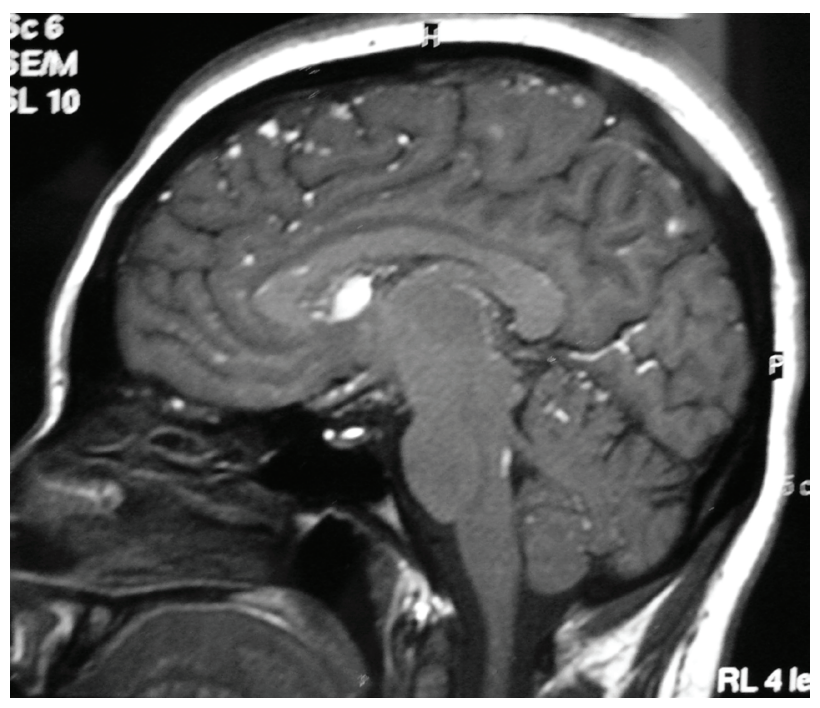

Figure 2. Sagittal T1-weighted sequence without gadolinium demonstrating the extent of the oily clots dissemination reaching the posterior fossa, the pituitary fossa, the optic nerves and the cortical sulci.

stopped the convulsions. She was also given a bolus of Phenobarbital and Phenytoin before getting awaked at the second day. Her neurological and neuropsychological examinations

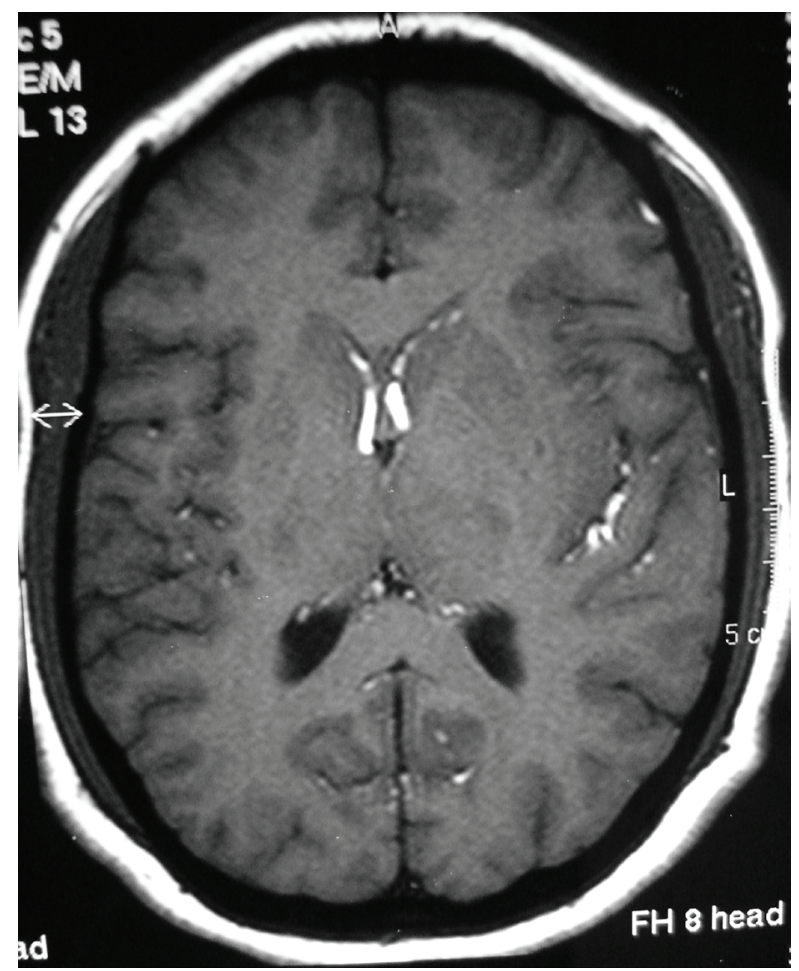

Figure 3. Axial T1-weighted sequence without contrast. Hyperintense clots spread to the left Sylvian fissure and within both lateral ventricles.

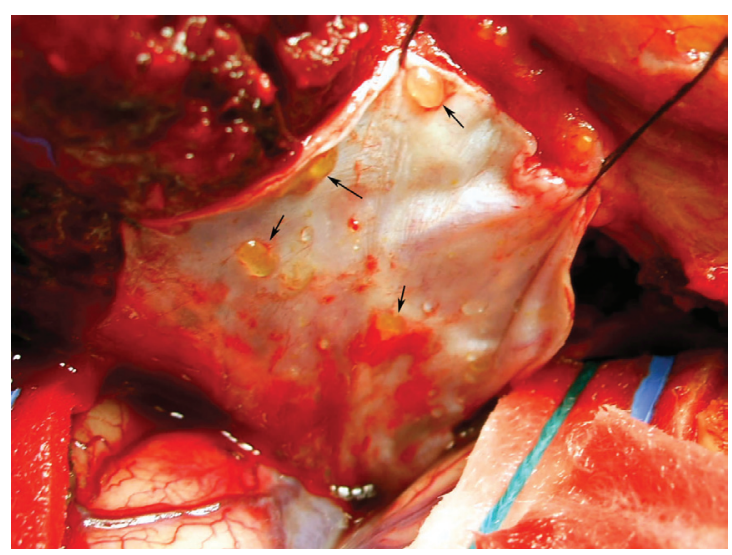

Figure 4. Peroperative view showing the subdural fatty clots adherent to the pterional dura (arrows).

were normal. Electroencephalography (EEG) showed left predominant periodic spikes. Magnetic resonance imaging (MRI) depicted a heterogeneous left temporal mass containing cystic portions, mainly composed of a fatty signal. The T1-weighted sequence showed fatty droplets within the left sylvian fissure, the subdural space and the superficial sulci (Fig. 1-3). A dermoid temporal cyst ruptured within the ventricles, the subarachnoid and subdural spaces was suspected. The patient underwent a left pterional approach. The opening of the dura discovered yellowish fatty clots adherent to the dura (Fig. 4). The white tumor was debulked with annular curettes removing a yellowish paste-like material containing hairs. The left sylvian artery and its temporal branches were very adherent to the capsule, leading to a subtotal removal of the cyst wall. The post-operative course was uneventful. The patient received five days of dexamethasone ( $16 \mathrm{mg} /$ day $)$ in order to prevent any further chemical meningeal irritation. The patient was discharged after seven days, with a normal neurological examination. Pathological examination of the mass confirmed the diagnosis of a dermoid cyst, showing a desquamated epithelium in the superficial layers, sebaceous glands and hair elements. At 32 months post-operatively, she was seizure-free with $300 \mathrm{mg} /$ day of phenytoin with a normal neurological examination and a stable temporal cyst remnant adherent to the left sylvian artery on the MRI.

\section{Discussion}

Intracranial dermoids account for $0.04-0.6 \%$ of all intracranial neoplasms [2]. As for epidermoids, dermoid cysts are congenital neoplasms, resulting from the inclusion of ectodermal elements during the neural tube closure, between the third and fifth week of embryonic life [3, 4]. Concerning the dermoid cysts, the peak incidence is estimated between 
the third and fifth decade of age, earlier than their epidermoid counterparts [4]. It has been suggested that dermoids grow more rapidly than epidermoids, leading thereby to an increased incidence of rupture and an earlier presentation $[1,2]$. The 'neoplastic' progression of such inclusion tumors doesn't result from the classical tumor cell division, but they enlarge because of cell desquamation and secretions of dermal glands [3]. The clinical history is related to their mass effect on the neural structures, and their slow rate of progression explains the considerable size they might reach. Rarely, as shown in our case, dermoids can rupture within the ventricular system, the subarachnoid or the subdural spaces [1, 2, 5-11]. Formerly, these incidents were considered to be dramatic [7]. However, the development and the availability of neuroimaging tools led to the multiplication of such diagnoses in pauci or asymptomatic patients [4]. The intra-cystic glandular secretions, possibly stimulated by age-related hormonal changes, might facilitate the dermoid's rupture [1]. This rupture may be spontaneous, at surgery, or following head trauma [1]. The clinical presentation of such an incident is variable, depending on the volume of the fatty spread and its location $[8,9]$. In a review of the literature (44 patients), Stendel [1] reported a wide variety of symptoms including headache (31.8\%), seizures (29.5\%), temporary sensory or motor hemi-syndrome $(15.9 \%)$, and chemical meningitis $(6.9 \%)$. Only one fatal outcome was found $(2.3 \%)$. The review of the literature confirms that the major signs of dermoids rupture remain headache and seizures $(50 \%)$, as shown in our case, probably secondary to the irritation of the subarachnoid spaces by the fatty droplets [2]. The presence of these droplets has been incriminated in the genesis of vasospasm, which has been well documented in animals but not yet in humans [12]. Status epilepticus has exceptionally been reported [11]. Most ruptured dermoids described in the literature, involved the supratentorial floor (sellar region $34.1 \%$, frontal lobe $29.6 \%$, temporal $13.6 \%$ ) while the posterior fossa was concerned in only $4.5 \%$ [1]. Concerning the dermoids' features associated with cyst rupture, only the supratentorial location was shown to be more purveyor of rupture comparatively to the infratentorial ones, probably because these latter are often less bulky [5]. Besides, a change of the cyst intensity on the MRI might predict a risk of rupture, probably due to the fat accumulation within the dermoid [13]. It is important to note that even spinal dermoids may spread fat within the intra-cranial space [8], confirming the necessity of additional spinal MR examination.

The treatment is exclusively surgical, requiring the removal of the cyst and its content. However, the adherences between the cyst capsule and the surrounding structures (vessels and cranial nerves) may lead to subtotal removal. This latter might be a good compromise in order to avoid any neurological unacceptable deficits in this benign slowgrowing tumor [14-16]. Only few cases of recurrence of dermoid cysts $[3,6]$ after subtotal removal have been reported in the literature, contrary to their epidermoids counterparts [16]. Seizures, probably secondary to the chemical irritation caused by the fatty clots left in the cisterns, can even develop later after the dermoids' removal [10].

\section{References}

1. Stendel R, Pietila TA, Lehmann K, Kurth R, Suess O, Brock M. Ruptured intracranial dermoid cysts. Surg Neurol 2002;57(6):391-398; discussion 398.

2. Johnson DG, Stemper SJ, Withers TK. Ruptured "giant" supratentorial dermoid cyst. J Clin Neurosci 2005;12(2):198-201.

3. Arseni C, Danaila L, Constantinescu AI, Carp N, Decu P. Cerebral dermoid tumours. Neurochirurgia (Stuttg) 1976;19(3):104-114.

4. Osbourn AG, Tong KA. Handbook of Neuroradiology: Brain and Skull. 2nd edn. New York: CV Mosby 1996; 322-327.

5. Dagher AP, Smirniotopoulos J. Intracranial dermoids cysts with and without rupture. International Journal of Neuroradiology 1995; 1: 134-44.

6. Jamjoom AB, Cummins BH. The diagnosis of ruptured intracranial dermoid cysts. $\mathrm{Br} \mathrm{J}$ Neurosurg 1989;3(5):609-612.

7. Manlapaz JS. Ruptured intracranial dermoid; report of a case and survey of previously reported cases. Am J Surg 1960;100(723-730.

8. Scearce TA, Shaw CM, Bronstein AD, Swanson PD. Intraventricular fat from a ruptured sacral dermoid cyst: clinical, radiographic, and pathological correlation. Case report. J Neurosurg 1993;78(4):666-668.

9. Takeuchi H, Kubota T, Kabuto M, Izaki K. Ruptured suprasellar dermoid cyst presenting olfactory delusion (Eigengeruchs erlebnis). Neurosurgery 1993;33(1):97-99.

10. Yoshimoto K, Nishio S, Suzuki S, Fukui M, Hasuo K. Movable oil in the brain: intracranial ruptured dermoid tumors. Case illustration. J Neurosurg 1997;86(4):734.

11. Van der Graaf M, Davies G. Status epilepticus due to a ruptured dermoid cyst. Journal of Neurology Neurosurgery and Psychiatry 1997; 62: 222.

12. Sasaki T, Wakai S, Asano T, Watanabe T, Kirino T, Sano $\mathrm{K}$. The effect of a lipid hydroperoxide of arachidonic acid on the canine basilar artery. An experimental study on cerebral vasospasm. J Neurosurg 1981;54(3):357365 .

13. Messori A, Polonara G, Serio A, Gambelli E, Salvolini U. Expanding experience with spontaneous dermoid rupture in the MRI era: diagnosis and follow-up. Eur J Radiol 2002;43(1):19-27.

14. Lunardi P, Missori P, Rizzo A, Gagliardi FM. Chemical meningitis in ruptured intracranial dermoid. Case report and review of the literature. Surg Neurol 1989;32(6):449- 
452.

15. Yasargil MG, Abernathey CD, Sarioglu AC. Microneurosurgical treatment of intracranial dermoid and epidermoid tumors. Neurosurgery 1989;24(4):561-567.
16. Talacchi A, Sala F, Alessandrini F, Turazzi S, Bricolo A. Assessment and surgical management of posterior fossa epidermoid tumors: report of 28 cases. Neurosurgery 1998;42(2):242-251; discussion 251-242. 